\title{
NÍVEIS DE PREVENÇÃO EM ENFERMAGEM \\ DO TRABALHO
}

Maria Jacyra de Campos Nogueira*

NOGUEIRA, M. J. de C. Níveis de prevenção em enfermagem do trabalho. Rev. Esc. Enf. USP, São Paulo, 16(3):275-284, 1982.

A autora, baseada nos conceitos sobre funçöes da enfermagem emitidas por HENDERSON e por HORTA e nos niveis de prevenção de LEAVELL \& CLARK, aborda o papel da enfermagem na saúde ocupacional no Brasil, descrevendo suscintamente suas atividades e ações na empresa.

\section{INTRODUÇÃO}

Segundo HENDERSON 2, "a função peculiar da enfermeira é dar assistência ao indivíduo doente ou sadio, no desempenho de atividades que contribuam para manter a saúde ou para recuperá-la (ou ter morte serena) - atividades que ele desempenharia só, se tivesse a força, a vontade ou o conhecimento necessários. E fazê-lo de modo que o ajude a ganhar sua independência o mais rápido possivel".

Para HORTA", "enfermagem é a arte de assistir ao ser humano (individuo, familia e comunidade), no atendimento de suas necessidades básicas, de torná-lo independente desta assistência, quando possivel, pelo ensino do auto-cuidado; de recuperar, manter e promover sua saúde em colaboração com outros profissionais". Para essa autora, ainda, assistir é fazer pelo ser humano tudo aquilo que ele não pode fazer por sí mesmo, ajudá-lo quando ele estiver parcialmente impossibilitado de se auto-cuidar, orientá-lo ou ensiná-lo, supervisioná-lo e encaminhá-lo a outros profissionais.

A enfermagem de saúde pública ou enfermagem comunitária, segundo a ORGANIZAÇÃO MUNDIAL DA SAÚDE ${ }^{6}$, tem como objetivo a assistência à comunidade; suas ações estão dirigidas à população como um todo e baseadas nos métodos da saúde pública e da enfermagem, para promover, manter e restaurar a saúde de indivíduos, famílias e grupos. O planejamento e a execução da assistência inclui, ainda, ações

- Professor Assistente Doutor do Departamento de Enfermagem Médico-Cirúrgica da Escola de Enfermagem da USP - dísciplinas Saúde da Comunidade e Enfermagem Preventiva e Comunitária. Doutor em Enfermagem. Enfermeira. 
de prevenção nos três niveis, atenção primária direta e mobilização de recursos individuais e coletivos.

A enfermagem do trabalho pode ser considerada como um ramo da enfermagem comunitária, do mesmo modo que esta pode ser considerada como um enfoque comunitário da enfermagem geral. Como tal, são utilizados não só os métodos e técnicas desta última, como, também, os da enfermagem comunitária, pois uma empresa pode ser considerada como uma coletividade; além disso a enfermagem utilizada no seu trabalho os métodos, técnicas e conhecimentos da saúde ocupacional.

$A(0)$ enfermeira(o) do trabalho dos serviços de saúde ocupacional participa do planejamento, execução e avaliação de programas de saúde para os trabalhadores, por meio de sua atuação técnico-administrativa; da prestação de assistência direta ou de delegação e supervisão da assistência prestada por pessoal auxiliar e de ensino e pesquisa na área de enfermagem do trabalho, para a promoção, proteção e recuperação da saúde do trabalhador ${ }^{5}$.

As tarefas principais desempenhadas pela(o) enfermeira(o) do trabalho são:

- coletar e analisar, juntamente com a equipe de saúde ocupacional os dados sócio-sanitários da população de empregados a ser atendida pelo serviço de saúde ocupacional de uma empresa;

- elaborar, juntamente com a equipe, normas técnicas e administrativas para o referido serviço;

- estabelecer, juntamente com a equipe, o programa de saúde para os empregados da empresa;

- coletar e analisar os dados referentes às necessidades de enfermagem do programa e os recursos humanos e materiais existentes na empresa e na comunidade;

- planejar e organizar o serviço de enfermagem do trabalho;

- dirigir os serviços de enfermagem do trabalho;

- planejar a assistência à clientela e prestar os cuidados mais complexos;

- delegar os cuidados menos complexos ao auxiliar de enfermagem do trabalho e supervisionar os cuidados que foram planejados por ela (ele);

- planejar, executar e avaliar programas de educação para a saúde dirigidos aos empregados;

- participar, juntamente com a equipe, nos programas de outros departamentos da empresa quando visam a saúde do empregado; 
- participar no ensino de enfermagem do trabalho e na supervisão de estagiários, quando necessário;

- planejar, executar e avaliar pesquisas em enfermagem do trabalho e participar de pesquisas em saúde ocupacional.

\section{NIVEIS DE PREVENÇÃO, AÇÕES E ATIVIDADES DA ENFERMAGEM DO TRABALHO}

De acordo com o que foi exposto, podemos deduzir que, além de atuar junto à coletividade da empresa no atendimento das necessidades humanas básicas, a(o) enfermeira(o) do trabalho deve conduzir todas as suas ações de acordo com os niveis de prevenção, responsabilidade inerente, também, à equipe de saúde ocupacional.

A apresentação das ações e atividades da enfermagem do trabalho utilizando os niveis de prevenção de LEAVELL \& CLARK $^{4}$ e BULHÖES ${ }^{1}$ encontram-se no quadro I a seguir. A definição das atividades, suas ações componentes e o elemento nuclear que seria responsável por elas, encontram-se no quadro II. 


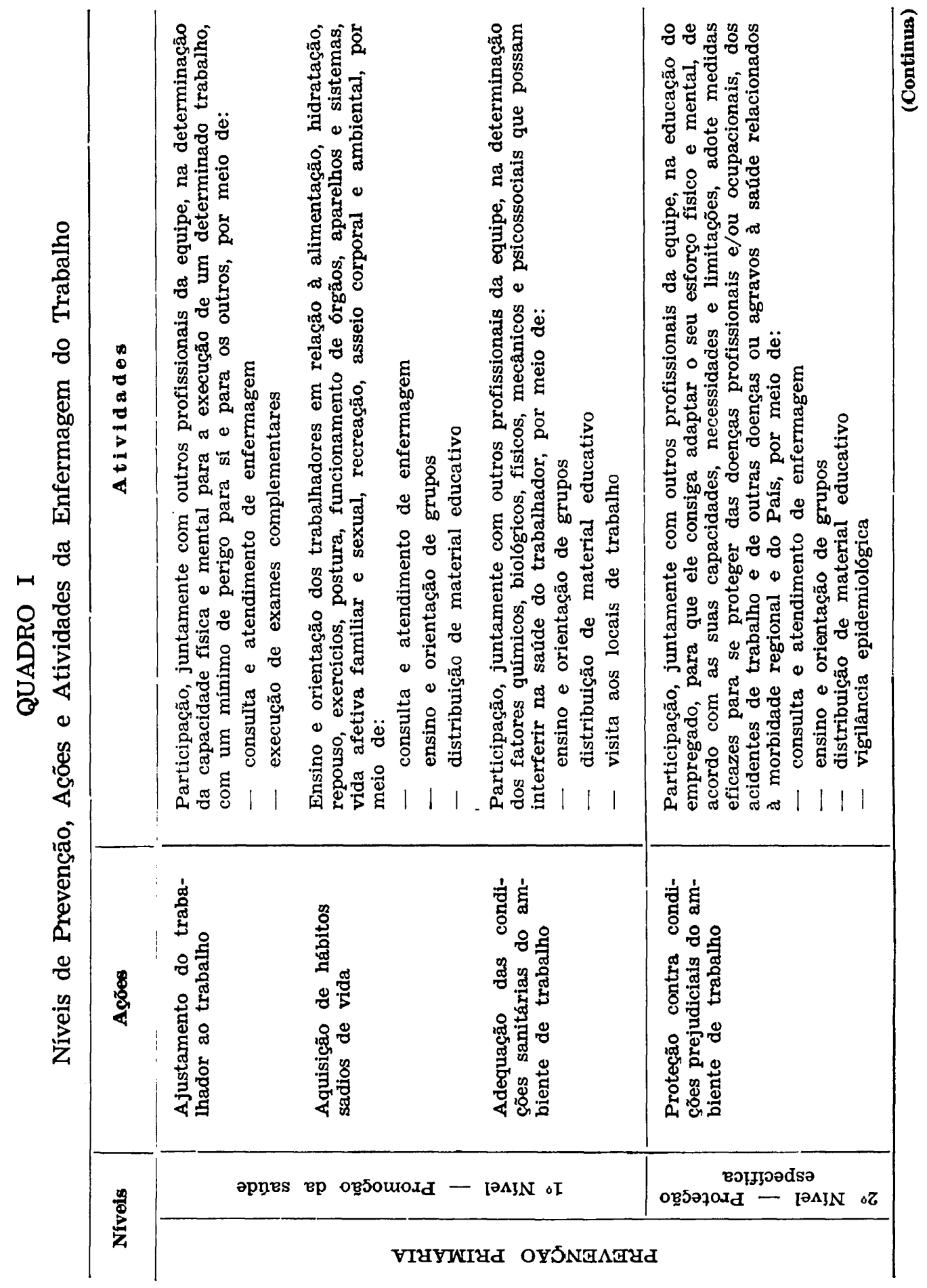




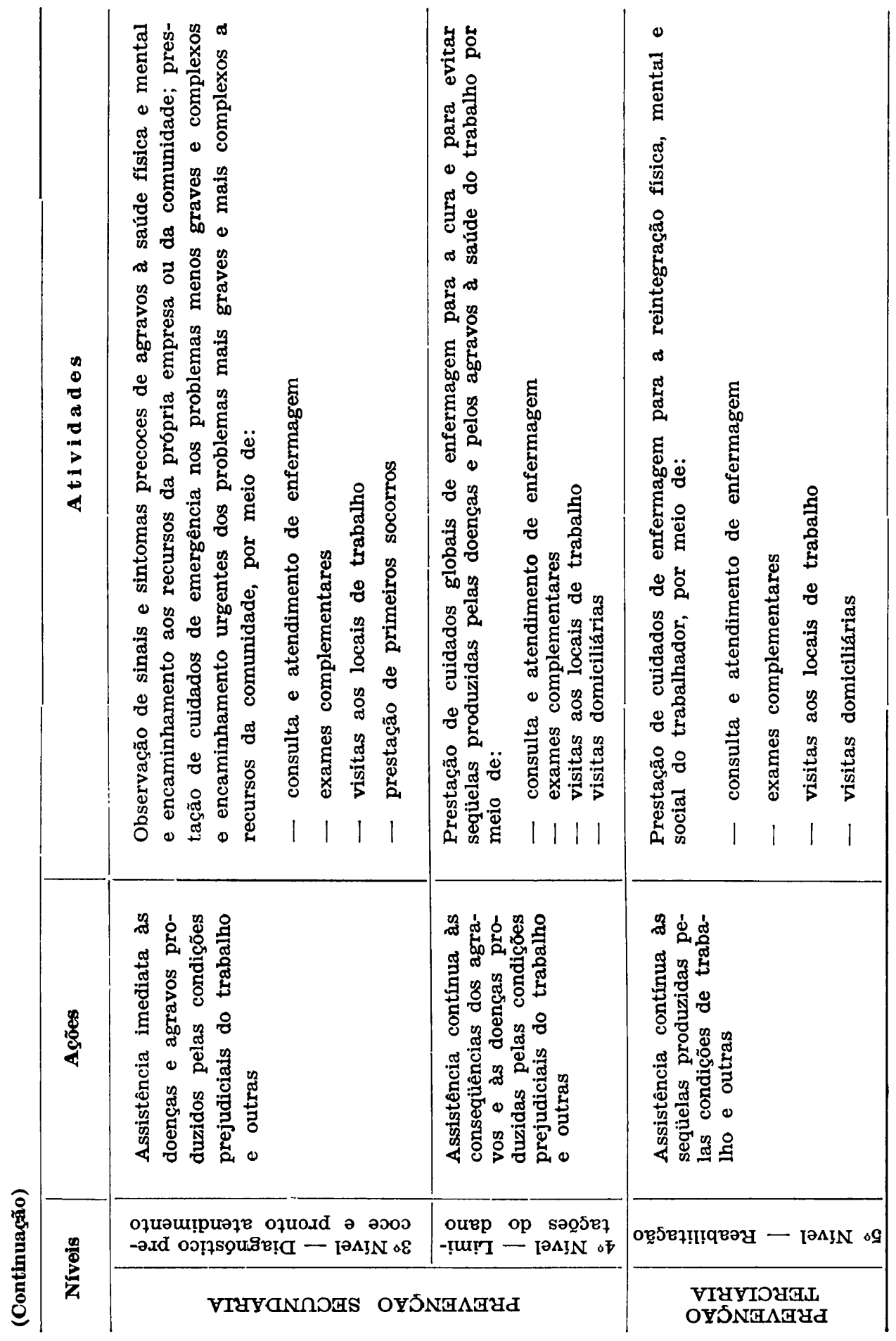




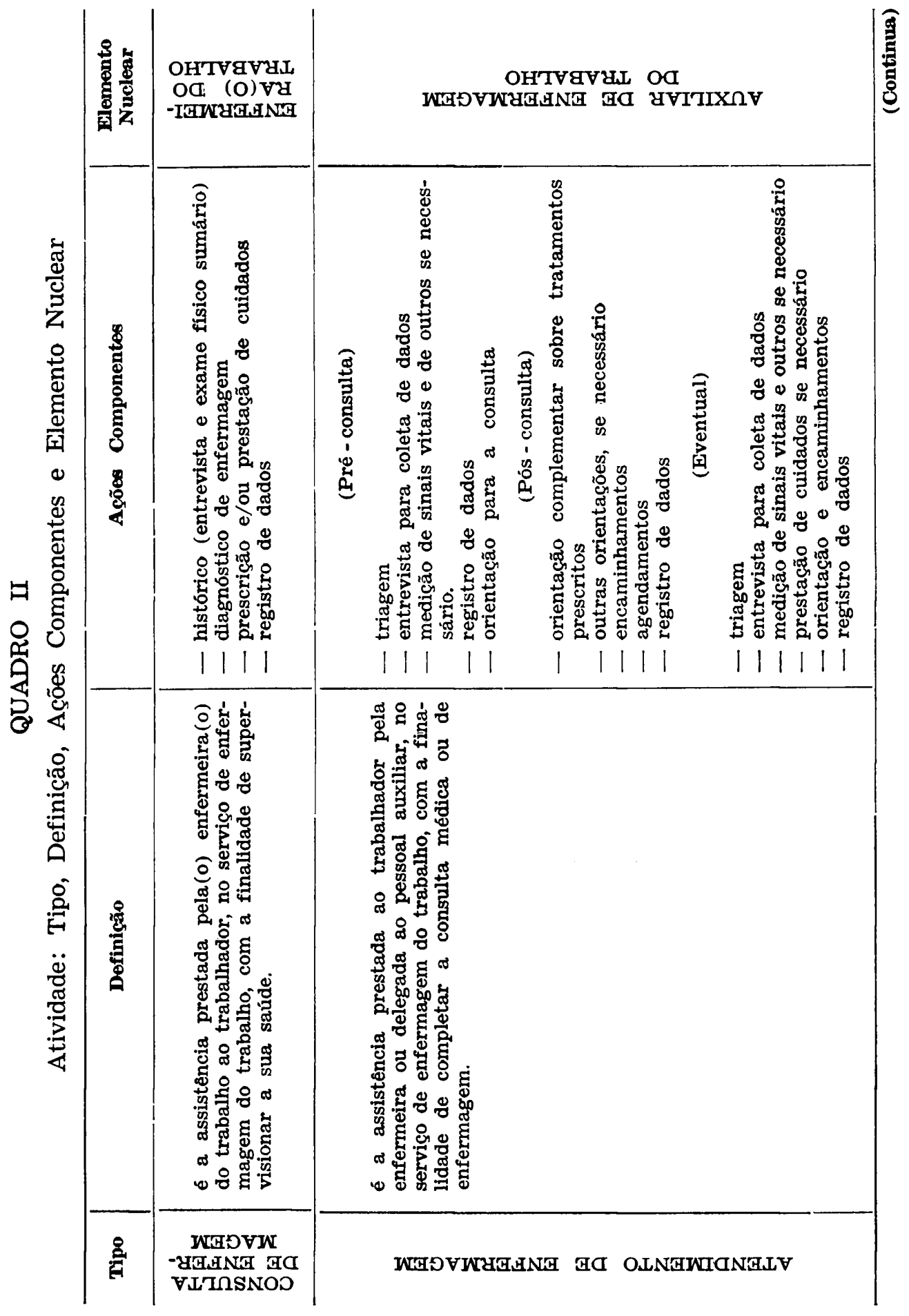




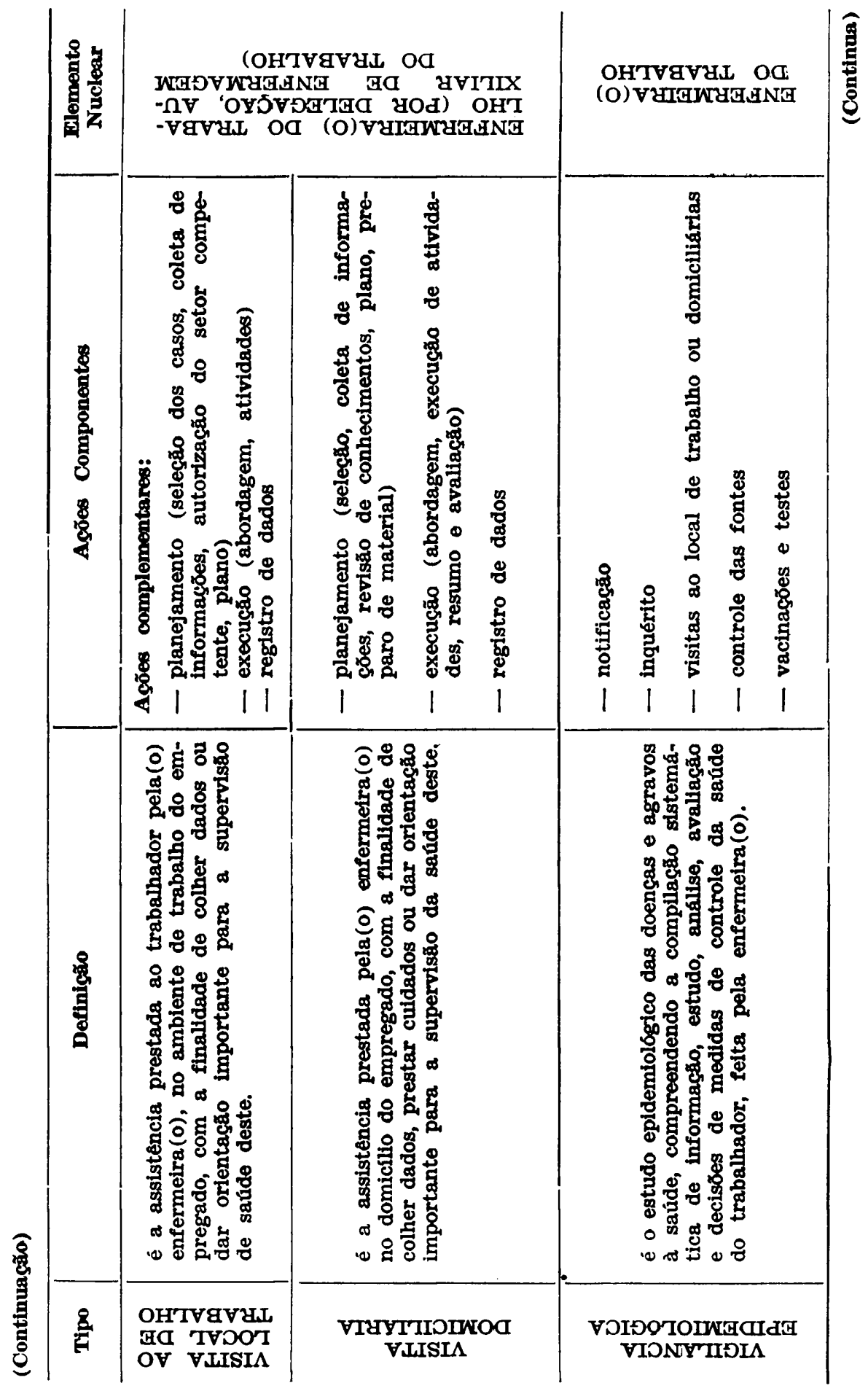




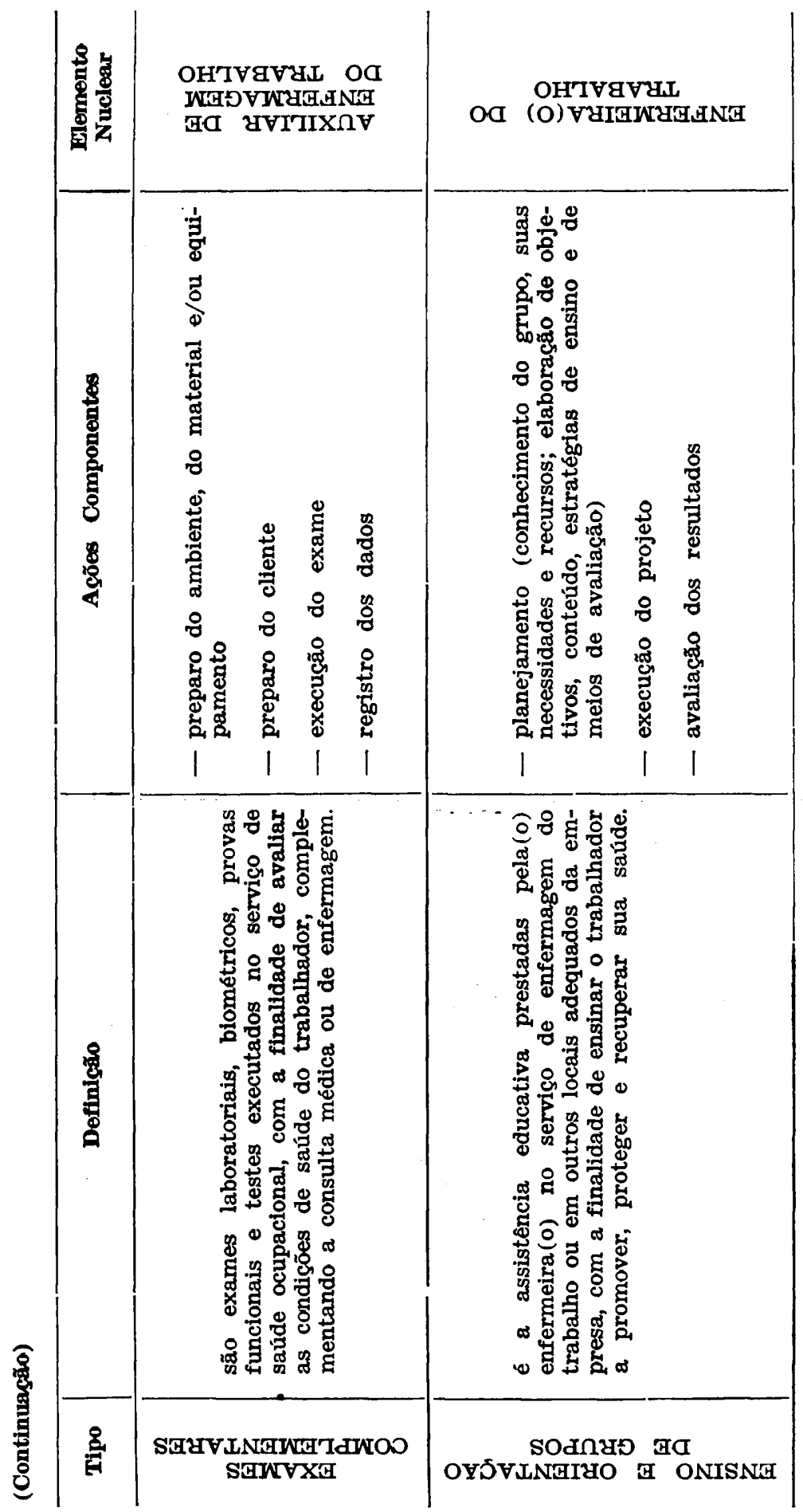


NOGUEIRA, M. J. de C. Prevention levels in occupational nursing. Rev. Esc. USP, São Paulo, $16(3): 275-284,1982$.

The autor, based in nursing functions concepts of HENDERSON and of HORTA, and in the prevention levels of LEAVELL \& CLARK, write about the of the occupational health nursing personnel in Brasil and describes their actions and activities.

\section{REFERENCIAS BIBLIOGRAFICAS}

1 - BULHOES, I. Enfermagem do trabalho. Rio de Janeiro, s.c.p. 1976 v. 1.

2 - HENDERSON, V. Princípios básicos sobre cuidados de enfermagem. Rio de Janeiro, ABEn, 1962. 62p.

3 - HORTA, W. de A. Enfermagem: teoria, conceitos, príncíplos e processo. Rev. Esc. Enf. USP, Săo Paulo, 8(1):7-15, mar. 1974.

4 - LEAVELL, H. R. \& CLARK, E. G. Medicina preventiva. São Paulo, Mc Graw-Hill, 1976. $744 \mathrm{p}$.

5 - NOGUEIRA, M. J. de C. Subsidios para a descrição do conteúdo global da ocupaçăo, enfermeira de saúde publica. Inf. Novas Dimens., Såo Paulo, 1(3):119-25, jul/ago, 1975 .

6 - ORGANIZACION MUNDIAL DE LA SALUD. Enseñanza de enfermeria en salud comunitaria. Washington, 1976. 19p. (Publicación Cientifica, 332). 